\title{
Bioconjugation of recombinant tissue plasminogen activator to magnetic nanocarriers for targeted thrombolysis
}

\author{
Hung-Wei Yangl,* \\ Mu-Yi Hua',* \\ Kun-Ju Lin ${ }^{2, *}$ \\ Shiaw-Pyng Wey ${ }^{3}$ \\ Rung-Ywan Tsai ${ }^{4}$ \\ Siao-Yun $\mathrm{Wu}^{5}$ \\ Yi-Ching $\mathrm{Lu}^{5}$ \\ Hao-Li Liu ${ }^{6}$ \\ Tony $\mathrm{Wu}^{7}$ \\ Yunn-Hwa $\mathrm{Ma}^{5}$ \\ 'Chang Gung Molecular Medicine Research \\ Center, Department of Chemical and \\ Materials Engineering, ${ }^{2}$ Molecular Imaging \\ Center, Department of Nuclear Medicine, \\ Chang Gung Memorial Hospital, Kuei-Shan, \\ Tao-Yuan, Taiwan, Republic of China; \\ ${ }^{3}$ Department of Medical Imaging and \\ Radiological Sciences, ${ }^{4}$ Electronics and \\ Optoelectronics Research Laboratories, \\ Industrial Technology Research Institute, \\ Hsin-chu, Taiwan, Republic of China; \\ ${ }^{5}$ Department of Physiology and \\ Pharmacology and Healthy Aging Research \\ Center, ${ }^{6}$ Department of Electrical \\ Engineering, Chang Gung University, \\ Kuei-Shan, Tao-Yuan, Taiwan, Republic \\ of China; ${ }^{7}$ Department of Neurology, \\ Chang Gung University College of Medicine \\ and Memorial Hospital, Tao-Yuan, Taiwan, \\ Republic of China \\ *These authors contributed equally \\ to this work
}

Correspondence: Yunn-Hwa Ma

Department of Physiology and Pharmacology

and Healthy Aging Research Center, Chang

Gung University, Kuei-Shan, Tao-Yuan 33302

Taiwan, Republic of China

Tel +88 632 । I 8 800, ext 5266

Fax +88632 II8700

Email yhma@mail.cgu.edu.tw

Tony Wu

Department of Neurology, Chang Gung

University College of Medicine and

Memorial Hospital, Tao-Yuan 33305

Taiwan, Republic of China

Tel +886 3328 I200, ext 24II2

$\mathrm{Fax}+88633285818$

Email tonywu@adm.cgmh.org.tw
This article was published in the following Dove Press journal:

International Journal of Nanomedicine

28 September 2012

Number of times this article has been viewed

\begin{abstract}
Low-toxicity magnetic nanocarriers (MNCs) composed of a shell of poly [aniline-co-N-(1-one-butyric acid) aniline] over a $\mathrm{Fe}_{3} \mathrm{O}_{4}$ magnetic nanoparticle core were developed to carry recombinant tissue plasminogen activator (rtPA) in MNC-rtPA for targeted thrombolysis. With an average diameter of $14.8 \mathrm{~nm}$, the MNCs exerted superparamagnetic properties. Up to $276 \mu \mathrm{g}$ of active rtPA was immobilized per mg of MNCs, and the stability of the immobilized rtPA was greatly improved during storage at $4^{\circ} \mathrm{C}$ and $25^{\circ} \mathrm{C}$. In vitro thrombolysis testing with a tubing system demonstrated that magnet-guided MNC-rtPA showed significantly improved thrombolysis compared with free rtPA and reduced the clot lysis time from $39.2 \pm 3.2$ minutes to $10.8 \pm 4.2$ minutes. In addition, magnet-guided MNC-rtPA at $20 \%$ of the regular rtPA dose restored blood flow within 15-25 minutes of treatment in a rat embolism model without triggering hematological toxicity. In conclusion, this improved system is based on magnetic targeting accelerated thrombolysis and is potentially amenable to therapeutic applications in thromboembolic diseases.
\end{abstract}

Keywords: thrombolysis, recombinant tissue plasminogen activator, magnetic nanocarriers, magnetic targeting, targeting therapy

\section{Introduction}

Thrombotic diseases, such as acute myocardial infarction and ischemic stroke, are the leading causes of death and disability in developed countries. In patients with thrombotic diseases, most plasmin is rapidly inactivated by the $\alpha 2$-plasmin inhibitor in the plasma. ${ }^{1}$ Plasminogen activators, such as urokinase, streptokinase, and recombinant tissue plasminogen activator (rtPA), are widely used in clinical thrombolytic therapy to induce plasmin formation, which degrades fibrin in blood clots and restores vascular flow. ${ }^{2-4}$ However, these fibrinolytic plasminogen activators may not be effectively conveyed to the site of thrombus because the vascular flow is slow in the obstructed blood vessel. To restore the flow efficiently, the dose of rtPA must be increased, but excessive plasma rtPA and its systemic distribution may cause serious hemorrhagic complications. Vascular flow is restored in approximately $50 \%$ of patients within 90 minutes after intravenous injection of rtPA for thrombolytic therapy, but approximately $20 \%$ of the patients exhibit serious side effects in the form of bleeding. ${ }^{5,6}$ Therefore, new approaches for treatment of thromboembolic diseases are needed. New drug-delivery systems have been developed to reduce the side effects of fibrinolytic agents and enhance their stability during storage and in blood circulation. Such systems may utilize liposomes, ${ }^{7}$ polymeric nanoparticles,${ }^{8}$ or magnetic carriers ${ }^{9-12}$ for delivery of fibrinolytic drugs to increase the efficiency of thrombolytic therapy. 
Magnetic nanocarriers (MNCs) for drugs are usually composed of an iron oxide core with superparamagnetic properties and a shell of hydrophilic polymers. The polymer shell may provide high-capacity functionalized surfaces that are capable of binding enzymes, ${ }^{13}$ inhibiting aggregation, and increasing the stability of drugs. ${ }^{14,15}$ MNCs can also be used for various biomedical applications, such as contrastenhancing agents for magnetic resonance imaging, ${ }^{16,17}$ magnetically guided drug targeting,,${ }^{9,18}$ enhancing enzyme stability for repeated use, ${ }^{13,19,20}$ and magnetic diagnosis. ${ }^{21} \mathrm{MNCs}$ also exhibit high drug-loading capacity and good stability in aqueous solutions as well as excellent biocompatibility with cells and tissues when used for drug delivery. ${ }^{22-29}$

We recently demonstrated the feasibility of targeting strategies for thrombolytic therapy in a rat embolic model using polyacrylic acid (PAA)-coated magnetic nanoparticles (PAA-MNPs) as the carrier for rtPA, which was covalently bound to PAA-MNPs through an amide bond. ${ }^{9}$ However, the technique was limited by the amount of rtPA loaded per PAA-MNP, which jeopardized further applications because of the risk of occluding the artery with the high amount of carrier required to achieve a therapeutic concentration of rtPA at the target site. In the current study, we presented biocompatible MNCs in which the drug-carrying capacity was improved by $\sim 50 \%$, which permitted a reduction of the quantity of MNCs required for the delivery of a specific dosage of rtPA and thus reduced the potential toxicity in thrombolytic therapy. Application of these MNCs represents a significant improvement for target thrombolysis.

\section{Material and methods \\ Bioconjugation of rtPA on MNCs}

The detailed procedures for the synthesis of poly[aniline-co$\mathrm{N}-(1$-one-butyric acid) aniline] (SPAnH) and MNPs were reported previously. ${ }^{27} \mathrm{MNCs}$ were generated by covering the MNPs cores with SPAnH shells. Twelve milligrams of 1-Et hyl-3-(3-dimethylaminopropyl)carbodiimide hydrochloride and $24 \mathrm{mg}$ of $\mathrm{N}$-hydroxysulfosuccinimide sodium salt were dissolved in $2 \mathrm{~mL}$ of $0.5 \mathrm{M}$ 2-(N-morpholino)ethanesulfonic acid hydrate (MES) buffer ( $\mathrm{pH}$ 6.3) in the dark. A 0.1-mL aliquot of this solution was mixed with $0.3 \mathrm{~mL}$ of MNCs $(8 \mathrm{mg} / \mathrm{mL})$ at $25^{\circ} \mathrm{C}$ and sonicated for $60 \mathrm{~min}$ utes in the dark. After separation, the MNCs were washed with $0.8 \mathrm{~mL}$ of $0.1 \mathrm{M}$ MES, resuspended in $0.2 \mathrm{~mL}$ of MES buffer, and mixed with $0.2 \mathrm{~mL}$ of rtPA at $25^{\circ} \mathrm{C}$. The solutions were then shaken for 2 hours at $25^{\circ} \mathrm{C}$. MNCs with rtPA immobilized on the surface (ie, MNC-rtPA) were separated from the solution by external magnet, washed with deion- ized (DI) water to remove unbound rtPA, and dispersed in $0.2 \mathrm{~mL}$ of DI water.

\section{Radiolabeling of MNCs with ${ }^{99 \mathrm{~m} T \mathrm{c}}$}

To prepare ${ }^{99 \mathrm{~m}} \mathrm{Tc}$-tagged MNCs for microSPECT imaging, $20 \mu \mathrm{L}$ of MNC-rtPA solution $(10 \mathrm{mg} / \mathrm{mL}$ MNCs with various concentrations of rtPA) and $20 \mathrm{mCi}{ }^{99 \mathrm{~m}} \mathrm{Tc}$-sodium pertechnetate (in $0.5 \mathrm{~mL}$ of normal saline) were added to a 1.5-mL tube. After the addition of $6 \mu \mathrm{L}$ of stannous chloride dehydrate (Sigma-Aldrich Chemical Co, St Louis, MO) solution $(4.5 \mathrm{mg} / \mathrm{mL}$ in $0.1 \mathrm{~N} \mathrm{HCl})$, the mixture was vortexed for 30 seconds and incubated at room temperature for 20 minutes. The radiolabeled MNCs were recovered from the mixture by precipitation on a magnet. The precipitated MNCs were washed twice with $0.5 \mathrm{~mL}$ of DI water to remove residual untagged ${ }^{99 \mathrm{~m}} \mathrm{Tc}$ and resuspended in $20 \mu \mathrm{L}$ of DI water. The radiochemical purity of the ${ }^{99 \mathrm{~m}} \mathrm{Tc}$-tagged MNCs $(>95 \%)$ was determined on an ITLC-SG strip (Gelman Sciences, Inc, Ann Arbor, MI) developed with acetone. The radiochromatogram was analyzed with a radioTLC scanner (AR-2000; Bioscan, Inc, Washington, DC).

\section{Characterization of MNCs and the binding capacity for rtPA}

The particle size and morphology of MNPs and MNCs were examined by transmission electron microscopy (TEM, H-7500; Hitachi, Ltd, Tokyo, Japan) operated at $100 \mathrm{kV}$. The samples were prepared by directly dropping the solution of MNPs and MNCs onto carbon-coated copper grids. The average zeta potential of the MNCs was measured by dynamic light scattering (DLS, ZEN3600 Zetasizer; Malvern Instruments Ltd, Malvern, UK). The spin density of the surface of the MNCs was measured by electron paramagnetic resonance spectroscopy (BRUKEREMX-10; Bruker AXS, Billerica, Germany) at $25^{\circ} \mathrm{C}$ and calibrated with diphenylpicrylhydrazine. The magnetization of the MNPs, the MNCs, and the MNC-rtPA was measured with a superconducting quantum interference device (MPMS-7; Quantum Design, Inc, San Diego, CA) at $25^{\circ} \mathrm{C}$ and a $\pm 4-\mathrm{kOe}$ applied magnetic field. Fourier transform infrared (FT-IR) spectroscopy (TENSOR 27; Bruker Optics, Billerica, MA) was performed with the $\mathrm{KBr}$ sample holder method. The concentration of carboxyl groups on the surface of the MNCs was measured by the Toluidine Blue $\mathrm{O}$ method..$^{30}$ The ratios of the SPAnH shells to the $\mathrm{Fe}_{3} \mathrm{O}_{4}$ cores were analyzed by inductively coupled plasma optical emission spectrometry (720-ES; Varian Inc, Palo Alto, CA). The binding capacity of rtPA immobilized on the MNCs was calculated by 
measuring the unbound rtPA concentration in the supernatant and washing solution; the binding capacity was expressed as the amount of rtPA $(\mu \mathrm{g})$ bound per mg of MNCs. The concentration was determined with a colorimetric method in a spectrophotometer (Thermo Scientific 20 Genesys; Thermo Fisher Scientific Inc, Waltham, MA) at $595 \mathrm{~nm}$ with the Protein Assay Kit from Bio-Rad (Hercules, CA) as described previously. ${ }^{31}$

\section{Kinetics of free rtPA and MNC-rtPA}

The kinetic parameters of free rtPA and MNC-rtPA were studied by the initial rate method with the Michaelis constant. $^{32}$ rtPA was reacted with different concentrations of $\mathrm{S}-2288^{\mathrm{TM}}(0.1-1.0 \mathrm{mM})$ at $25^{\circ} \mathrm{C}$ to calculate the $\mathrm{K}_{\mathrm{m}}$ and $\mathrm{V}_{\text {max }}$ values; $\mathrm{V}_{\max }$ is the highest possible reaction velocity when rtPA is saturated with substrate, and $\mathrm{K}_{\mathrm{m}}$ is the Michaelis constant, which is the substrate concentration that yields half the true maximum reaction velocity and represents the effective affinity between $\mathrm{rtPA}$ and the substrate. The $\mathrm{K}_{\mathrm{m}}$ and $\mathrm{V}_{\text {max }}$ values were calculated from the following equations: ${ }^{32}$

$$
\begin{aligned}
& \mathrm{E}+\mathrm{S} \underset{\mathrm{k}_{-1}}{\stackrel{\mathrm{k}_{1}}{\rightleftarrows}} \mathrm{ES} \stackrel{\mathrm{k}_{2}}{\longrightarrow} \mathrm{E}+\mathrm{P} \\
& \mathrm{V}=\frac{\mathrm{V}_{\text {max }}[\mathrm{S}]}{\mathrm{K}_{\mathrm{m}}+[\mathrm{S}]} \quad 1 / v=\frac{\mathrm{K}_{\mathrm{m}}}{\mathrm{V}_{\max }[\mathrm{S}]}+1 / \mathrm{V}_{\max } \\
& \left\{\begin{array}{l}
\mathrm{V}_{\text {max }}=\mathrm{k}_{2}[\mathrm{E}]_{\mathrm{t}} \\
\mathrm{K}_{\mathrm{m}}=\left(\mathrm{k}_{-1} / \mathrm{k}_{1}\right)
\end{array}\right.
\end{aligned}
$$

where $\mathrm{v}$ is the initial reaction velocity; $\mathrm{k}_{1}, \mathrm{k}_{-1}$, and $\mathrm{k}_{2}$ are rate constants; $[\mathrm{E}]$ is the concentration of rtPA; $[\mathrm{S}]$ is the concentration of S-2288 ${ }^{\mathrm{TM}}$; and $[\mathrm{P}]$ is the concentration of $\rho-\mathrm{Na}$.

\section{In vitro thrombolysis}

Human blood was collected and immediately placed in polyethylene tubes with an interior diameter of $5 \mathrm{~mm}$. The tubes were incubated horizontally at $37^{\circ} \mathrm{C}$ for 24 hours. The clot was removed from the tube, washed with saline, and cut into long pieces $(1 \times 2 \mathrm{~mm}$ or $2 \times 5 \mathrm{~mm})$. Platelet-poor plasma (PPP) was prepared by mixing $9 \mathrm{~mL}$ of human blood with $1 \mathrm{~mL}$ of sodium citrate solution; the PPP was then obtained by centrifugation at $6,000 \mathrm{rpm}$ for 20 minutes.

Thrombolysis without flow was investigated by adding $100 \mu \mathrm{L}$ of different concentrations of free rtPA or MNC-rtPA, and $800 \mu \mathrm{L}$ of saline to 5 -mL vials containing a $1 \times 2 \mathrm{~mm}$ clot, followed by shaking at $150 \mathrm{rpm}$ for 30 minutes. The optical absorbance of the supernatant at $405 \mathrm{~nm}\left(\mathrm{OD}_{405}\right)$ was then measured to calculate the amount of hemachrome.
Thrombolysis with flow was investigated by using a peristaltic pump at a fixed flow rate of $0.18 \mathrm{~mL} / \mathrm{min}$ to convey the mobile solution $(\mathrm{ppp} / \mathrm{saline}=1 / 4, \mathrm{v} / \mathrm{v})$. A $2 \times 5 \mathrm{~mm}$ clot was placed into a glass dropper (supporting information, Figure $\mathrm{S} 1$ ). Then, $50 \mu \mathrm{L}$ of a solution containing $250 \mu \mathrm{g}$ of free rtPA or an equivalent amount of MNC-rtPA was slowly injected $10 \mathrm{~cm}$ upstream in the clot on the left. The magnetic field was applied at the injection site to guide the MNC-rtPA, shifted slowly to the clot area, and remained in place for 5 minutes. The time at which the clot flowed out of the tip of the glass dropper was measured and defined as the clot lysis time.

\section{In vivo biodistribution}

The biodistribution of the MNCs was studied in rats by single-photon emission computed tomography (SPECT)/ computed tomography (CT) (NanoSPECT/CT; Bioscan Inc) with a ${ }^{99 \mathrm{~m}}$ Tc-pertechnetate radiolabeled test drug. The rat embolic model was prepared under anesthesia as described below. Scintigraphy was performed immediately after the injection of $6 \mathrm{mCi}^{99 \mathrm{~m}} \mathrm{Tc}-\mathrm{MNCs}$ into the left iliac artery via a catheter in the right iliac artery. Dynamic planar images were collected at 10-second intervals up to 1 hour after the administration of the test drug. The scintigraphic images were quantitatively analyzed to evaluate the distribution of ${ }^{99 m}$ Tc-MNCs within the systemic circulation. The mean radioactivity counts within the left hind limb and bilateral forelimbs were calculated. The image intensities were normalized to steady blood pool mean counts of bilateral forelimbs around 10 minutes post injection for comparison.

\section{Rat embolic model}

The rat iliac embolism model was modified from a previous study, ${ }^{33}$ and the protocol was approved by the Institutional Animal Care and Use Committee. Briefly, 9-week-old male Sprague-Dawley rats $(340 \pm 3 \mathrm{~g}, \mathrm{n}=28)$ were anesthetized by intraperitoneal injection of Inactin ${ }^{\circledR}$ (thiobutabarbital sodium $100 \mathrm{mg} / \mathrm{kg}$; Sigma-Aldrich Co), followed by tracheostomy and cannulation of the carotid artery for continuous blood pressure measurement; the heart rate recording was triggered by the pulsatile output of the blood pressure. The right iliac artery was cannulated with a catheter, with the tip reaching the bifurcation of the abdominal aorta and iliac arteries to inject a piece of whole blood clot $(1.5 \times 2 \mathrm{~mm}), \mathrm{MNCs}$, and MNC-rtPA, as described previously. ${ }^{9}$ Hemodynamic measurements were obtained at the abdominal aorta and left iliac arteries by ultrasonic flowmetry (T206; Transonic System Inc, Ithaca, NY) with $1.5 \mathrm{RB}$ and $1 \mathrm{RB}$ probes, respectively; 
the tissue perfusion levels of the left hind limb and cremaster muscle were determined with a laser Doppler perfusion imager (MoorFLPI; Moor Instruments Ltd, Wilmington, DE). After a 20-minute equilibration period, a piece of whole blood clot $(1.5 \times 2 \mathrm{~mm})$ was injected and lodged in the left iliac artery; however, the observation and drug intervention only continued when a clot induced an immediate reduction of the left iliac flow to less than $1 \mathrm{~mL} /$ minute. After 5 minutes, MNCs or MNC-rtPA were injected and guided using an $\mathrm{NdFeB}$ magnet of 0.5-Tesla (T). The magnet was guided back and forth between the bifurcation and the femoral artery at a frequency of once every 6-10 seconds. The hemodynamic responses to treatment with MNCs or MNC-rtPA were continuously monitored for 2 hours. The reperfusion time was defined as time required allowing iliac blood flow recovery to its $50 \%$ of basal level after thrombolysis treatment. At the end of some experiments, blood samples were obtained by cardiac puncture and analyzed with Sysmex XE-2100 (Sysmex Corporation, Kobe, Japan) at the Chang Gung Memorial Hospital. The results were presented as mean \pm standard error (SE). The responses of rats receiving different treatments were examined by a two-way analysis of variance with repeated measures, followed by Duncan's post-hoc test. Statistical significance was defined as $P<0.05$.

\section{Results}

\section{Characterization of MNCs}

The diameters of the MNPs and MNCs, as measured by TEM, were 12.0 and $14.8 \mathrm{~nm}$, respectively, which suggests that the thickness of the polymer shell was $\sim 1.4 \mathrm{~nm}$ (Figure 1A). The concentration of carboxyl groups on the surface per milligram of MNCs was $\sim 3.2 \pm 0.5$ mole, as measured by the toluidine blue $\mathrm{O}$ assay. The diffraction patterns of the MNCs measured by TEM matched the five crystal planes

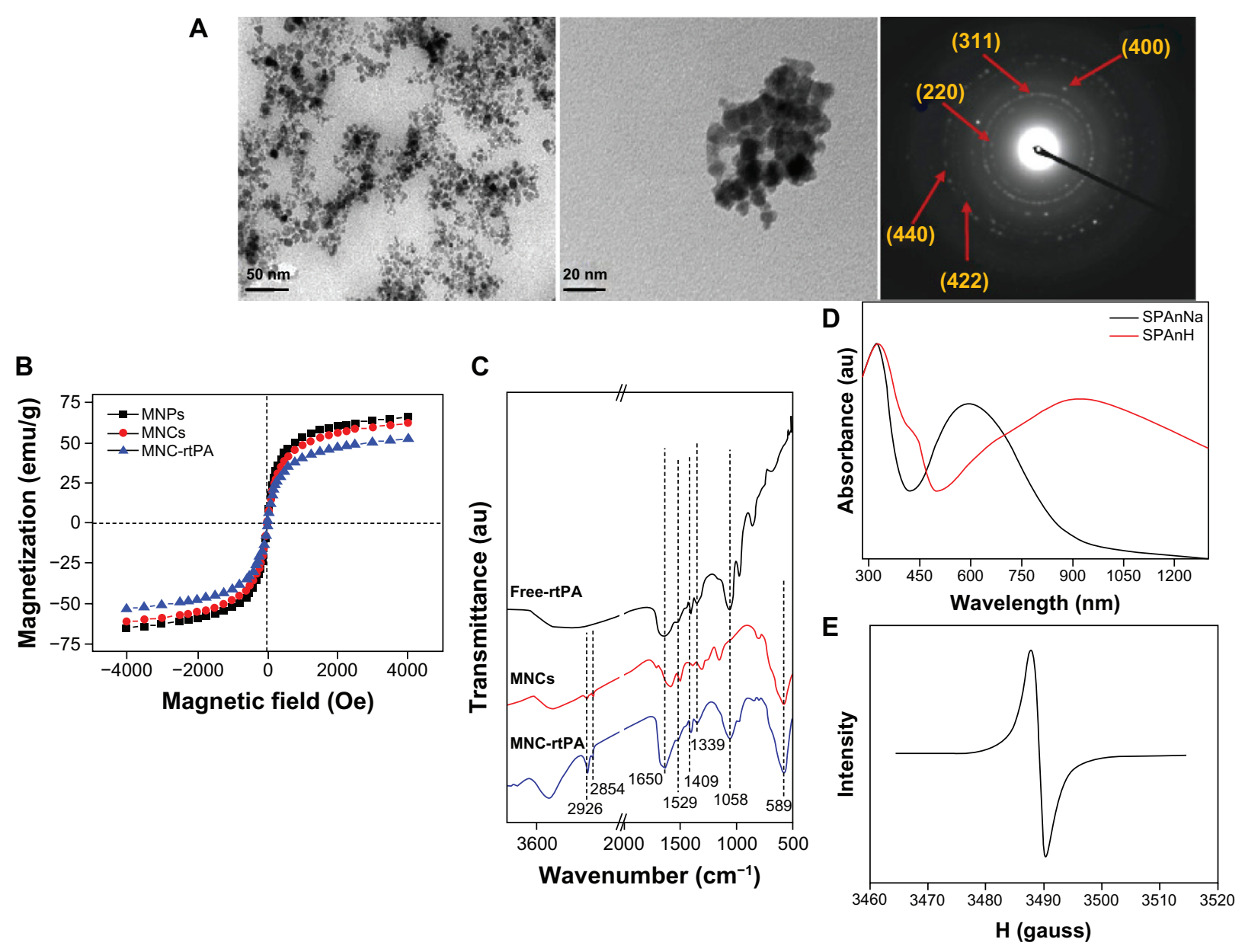

Figure I (A) Transmission electron micrographs of MNPs (left) and MNCs (middle) and the diffraction pattern of MNCs (right). (B) Superconducting quantum interference spectra of MNPs, MNCs and MNC-rtPA at room temperature. (C) FT-IR spectra of free rtPA, MNCs, and MNC-rtPA at room temperature. (D) UV-Vis spectra of SPAnNa and SPAnH at room temperature. (E) ESR measurement of SPAnH.

Abbreviations: TEM, transmission electron micrograph; MNPs, magnetic nanoparticles; MNCs, magnetic nanocarriers; rtPA, recombinant tissue plasminogen activator; FTIR, Fourier transform infrared spectroscopy; UV-Vis, ultraviolet-visible spectroscopy; SPAnNa, poly[aniline-co-sodium N-(I-one-butyric acid) aniline]; SPAnH, poly[anilineco-N-(I-one-butyric acid) aniline]; ESR, electron spin resonance. 
of $\mathrm{Fe}_{3} \mathrm{O}_{4}$ at 400, 311, 422, 220, and 440 indexed by the Joint Committee on Powder Diffraction Standards. ${ }^{34}$ The saturated magnetization decreased from 66.2 electromagnetic units (emu)/g for MNPs to $62.5 \mathrm{emu} / \mathrm{g}$ for MNCs, and then decreased to 52.5 electromagnetic units $(\mathrm{emu}) / \mathrm{g}$ for MNCrtPA as measured by superconducting quantum interference device with an applied magnetic field of $\pm 4 \mathrm{kOe}$ at room temperature, which correlated with the proportional decrease of MNPs within one gram of MNCs and MNC-rtPA. All samples displayed superparamagnetic properties (Figure 1B).

The FT-IR spectrum of the free rtPA, MNCs, and MNC-rtPA is shown in Figure 1C. After conjugation, five peaks characteristic of free rtPA were present at $1650 \mathrm{~cm}^{-1}$, $1529 \mathrm{~cm}^{-1}, 1409 \mathrm{~cm}^{-1}, 1339 \mathrm{~cm}^{-1}$, and $1058 \mathrm{~cm}^{-1}$ in the FT-IR spectrum of MNC-rtPA; the two peaks at $1650 \mathrm{~cm}^{-1}$ and $1529 \mathrm{~cm}^{-1}$ were characteristic bands for a protein. ${ }^{20} \mathrm{In}$ addition, the saturated symmetrical and asymmetrical stretch vibrations of C-H were observed at $2854 \mathrm{~cm}^{-1}$ and $2926 \mathrm{~cm}^{-1}$, respectively, and the stretch vibration of $\mathrm{Fe}-\mathrm{O}$ at $589 \mathrm{~cm}^{-1}$ was still observed for the MNCs. FT-IR revealed that the MNPs surface was covered with a shell of SPAnH, and the rtPA was immobilized on the outermost layer of the MNCs.

The electronic spectra of aqueous solutions of poly[anilineco-sodium N-(1-one-butyric acid) aniline] (SPAnNa) and SPAnH are shown in Figure 1D. The absorption peaks at $320-330 \mathrm{~nm}\left(\pi-\pi^{*}\right.$ transition of the benzenoid ring) and $596 \mathrm{~nm}$ (exciton transition of the quinone ring) for SPAnNa were obtained. HCl-doping and self-acid-doping were used to transform SPAnNa to SPAnH, and two new absorption peaks at $400-450 \mathrm{~nm}$ (polaron band) and $926 \mathrm{~nm}$ (bipolaron band) appeared. The electron spin resonance signal (Figure 1E) demonstrated that the peak-to-peak line width $(\Delta \mathrm{Hpp})$ was $2.49 \mathrm{G}$, the spin density was $3.04 \times 10^{20} \mathrm{spin} / \mathrm{g}$, and the $g$ value was 2.0037, which confirmed the resonance of free electrons delocalized in the $\pi$-system of the carbon atoms forming the SPAnH backbone in the main chain. ${ }^{35}$ The results indicate that many electron-hole pairs were produced on the main chain of SPAnH, thereby providing positively charged carriers.

\section{Quantification and activity of MNC-rtPA and thermal stability}

The amount of rtPA bound to the MNCs was measured by a chromogenic substrate assay (supplementary methods) as shown in Figure 2A. The quantity of rtPA immobilized on $1 \mathrm{mg}$ of MNCs increased with increasing concentrations of added rtPA; up to $430 \mu \mathrm{g}$ of rtPA bound to $1 \mathrm{mg}$ of MNCs. However, the specific activity of MNC-rtPA decreased with increasing concentrations of added rtPA. When the quantity of the rtPA bound to $1 \mathrm{mg}$ of MNCs was increased from $132 \mu \mathrm{g}$ to $430 \mu \mathrm{g}$, the specific activity decreased from $82.0 \%$ to $52.8 \%$.

The thermal stability of the free rtPA and MNC-rtPA in the DI water after storage at $4{ }^{\circ} \mathrm{C}, 25^{\circ} \mathrm{C}$, and $37^{\circ} \mathrm{C}$ were measured using a substrate assay (Figure 2B). Free rtPA quickly lost its original activity after storage with time, but MNC-rtPA maintained $73 \%$ and $25 \%$ of its initial activity after storage at $25^{\circ} \mathrm{C}$ and $37^{\circ} \mathrm{C}$ for 35 days, respectively. After storage at $4{ }^{\circ} \mathrm{C}$ for 35 days, $32 \%$ versus $80 \%$ of the initial enzymatic activity of the free versus immobilized rtPA remained, respectively.

\section{Study of drug kinetics}

The kinetic parameters $\mathrm{V}_{\max }$ and $\mathrm{K}_{\mathrm{m}}$ for the free rtPA and MNC-rtPA were assayed using S-2288 ${ }^{\mathrm{TM}}$ (Chromogenix, Milano, Italy) as the substrate agent (Supporting Information, Figure S2) and were calculated from Lineweaver-Burk plots. The $\mathrm{V}_{\max }$ of the free rtPA was $7.12 \mathrm{U} / \mathrm{mg}$ rtPA, which was higher than the value for MNC-rtPA (5.95 U/mg rtPA); whereas

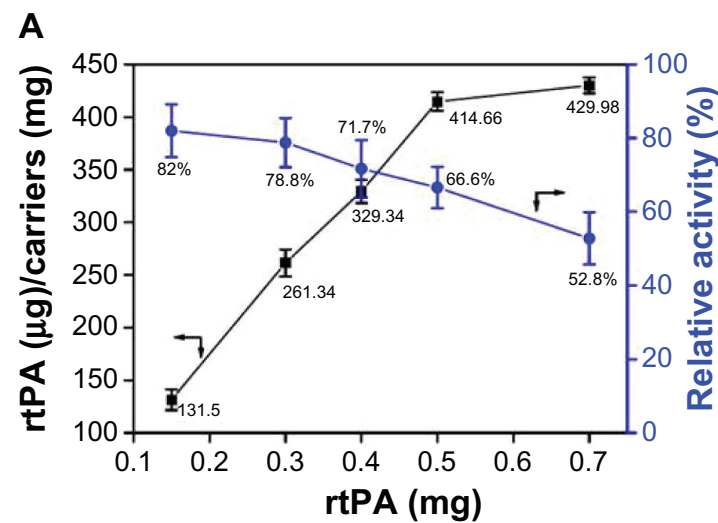

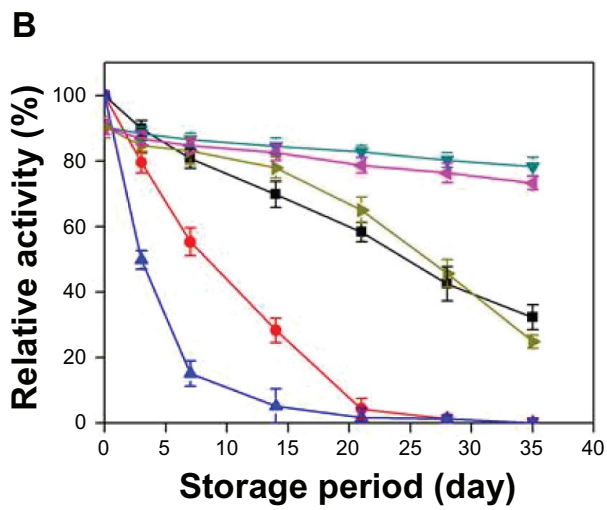

Figure 2 (A) Quantification and activity of MNC-rtPA in I mg of MNCs versus added rtPA. Values are the means \pm SD $(n=8)$. (B) Storage stability of free rtPA at $4^{\circ} \mathrm{C}(\boldsymbol{\bullet})$, free $\operatorname{rtPA}$ at $25^{\circ} \mathrm{C}(\bullet)$, free $r$ PA at $37^{\circ} \mathrm{C}(\Delta)$, and MNC-rtPA at $4^{\circ} \mathrm{C}(\nabla), \mathrm{MNC}-r \mathrm{PA}$ at $25^{\circ} \mathrm{C}(\triangleleft), \mathrm{MNC}-\mathrm{rtPA}$ at $37^{\circ} \mathrm{C}(\bullet)$.

Note: Values are the means \pm SD $(n=8)$.

Abbreviations: MNC, magnetic nanocarriers; rtPA, recombinant tissue plasminogen activator. 
the $\mathrm{K}_{\mathrm{m}}$ values for S-2288 ${ }^{\mathrm{TM}}$ and MNC-rtPA (4.39 mM) were higher than that of the free rtPA $(3.50 \mathrm{mM})$. The affinity between rtPA and the substrate decreased as the $\mathrm{K}_{\mathrm{m}}$ value increased. These data indicate that the affinity between MNCrtPA and the substrate decreased when compared with free rtPA. This effect may result from steric effects and the limited freedom of the activity site following the immobilization of rtPA on the surface of the MNC, which hinders the approach of the substrate to the active site of MNC-rtPA.

\section{In vitro cytotoxicity}

The cytotoxicity of the MNCs to human umbilical vein endothelial cells (HUVECs) was determined by the XTT assay method (supplementary methods). After 48 hours, HUVECs co-cultured with MNCs remained viable up to MNC concentrations of $150 \mu \mathrm{g} / \mathrm{mL}$, even when a magnetic field was applied under the culture plates (Figure 3A). The cytotoxicity was also evaluated by fluorescence microscopy of HUVECs continuously co-cultured with MNCs over a 7-day culture period; the cell viability and growth rate were not different from those of the control (Figure 3B). These results suggest that the MNCs have good biocompatibility with low cellular toxicity. The rtPA may induce cytotoxic effects in various types of the cells including vascular endothelial cells. We thus used effective rtPA of $480 \mu \mathrm{g} / \mathrm{mL}$ in testing for cytotoxicity among HUVECs (Figure S3). The MNC-rtPA did not exert significant influence on cell growth compared with that of control or free rtPA groups.

\section{In vitro thrombolysis}

The in vitro thrombolysis of clots in the absence of flow was investigated for MNCs, free rtPA, or MNC-rtPA
(Figure 4). The efficiency of thrombolysis was determined by measuring the $\mathrm{OD}_{405}$ after 30 minutes of reaction. The control (Figure 4A) and MNCs (Figure 4D) groups did not display any thrombolysis, even when a magnetic field was applied under the MNCs (Figure 4F) for 30 minutes. Furthermore, free rtPA (62 $\mu \mathrm{g}$, Figure 4B) and MNC-rtPA (effective $62 \mu \mathrm{g}$ rtPA, Figure 4C) obviously dissolved the clots; the $\mathrm{OD}_{405}$ values of free rtPA and MNC-rtPA were $0.551 \pm 0.073$ and $0.558 \pm 0.094$, respectively. The results suggest that the conjugation of rtPA to the MNCs preserved the enzymatic activity of rtPA and allowed for thrombolysis. However, the $\mathrm{OD}_{405}$ increased to $0.725 \pm 0.112$ in the presence of an applied magnetic field under the vials during thrombolysis (Figure 4E).

The in vitro thrombolysis of clots in the presence of flow was investigated by adding free rtPA and MNC-rtPA while applying a magnetic field of 0.3-T. At 10 minutes after injection, the clot was lysed by magnet-guided MNC-rtPA, but not by free rtPA (Figure 5A). The lysis times of the clot for the control group without any treatment and for the MNC solution were $91.7 \pm 3.9$ minutes and $86.6 \pm 5.2$ minutes, respectively (Figure 5B). However, the lysis time of the clot treated by injecting free rtPA $(250 \mu \mathrm{g})$ was $39.2 \pm 3.2$ minutes, which was longer than that of an equivalent effective concentration of rtPA in MNC-rtPA, which was guided to the clot site by an applied magnetic field (10.8 \pm 4.2 minutes) (Figure $5 \mathrm{~B})$.

\section{In vivo biodistribution of MNCs}

Dynamic scintigraphy showed the early passage of radiolabeled NMCs into the abdominal aorta via a venous catheter. With magnetic guidance, an increased accumulation of ${ }^{99 \mathrm{~m}}$ Tc-MNCs in the soft tissue of the left hind limb was
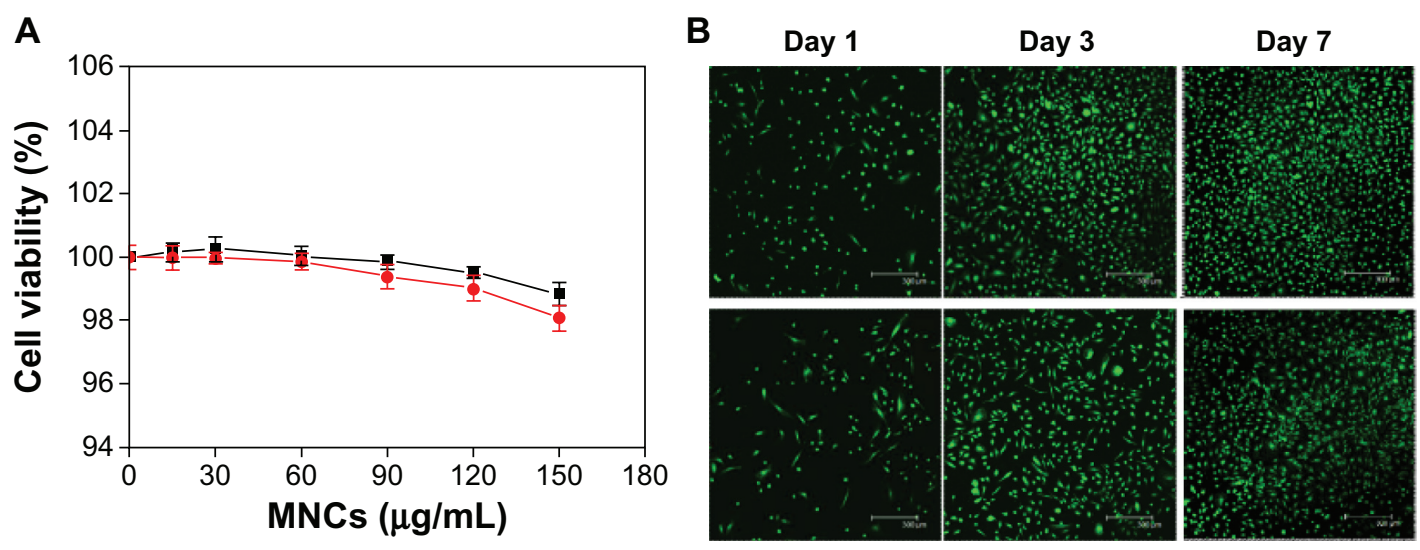

Figure 3 (A) Cytotoxicity of MNCs in HUVECs without $(\bullet)$ and with $(\bullet)$ an applied magnetic field of $800-$ G. (B) Fluorescence micrographs of control (top) and MNCs (bottom) in HUVECs after I, 3 , and 7 days.

Note: Values are the means $\pm S D(n=8)$.

Abbreviations: MNC, magnetic nanocarrier; rtPA, recombinant tissue plasminogen activator. 

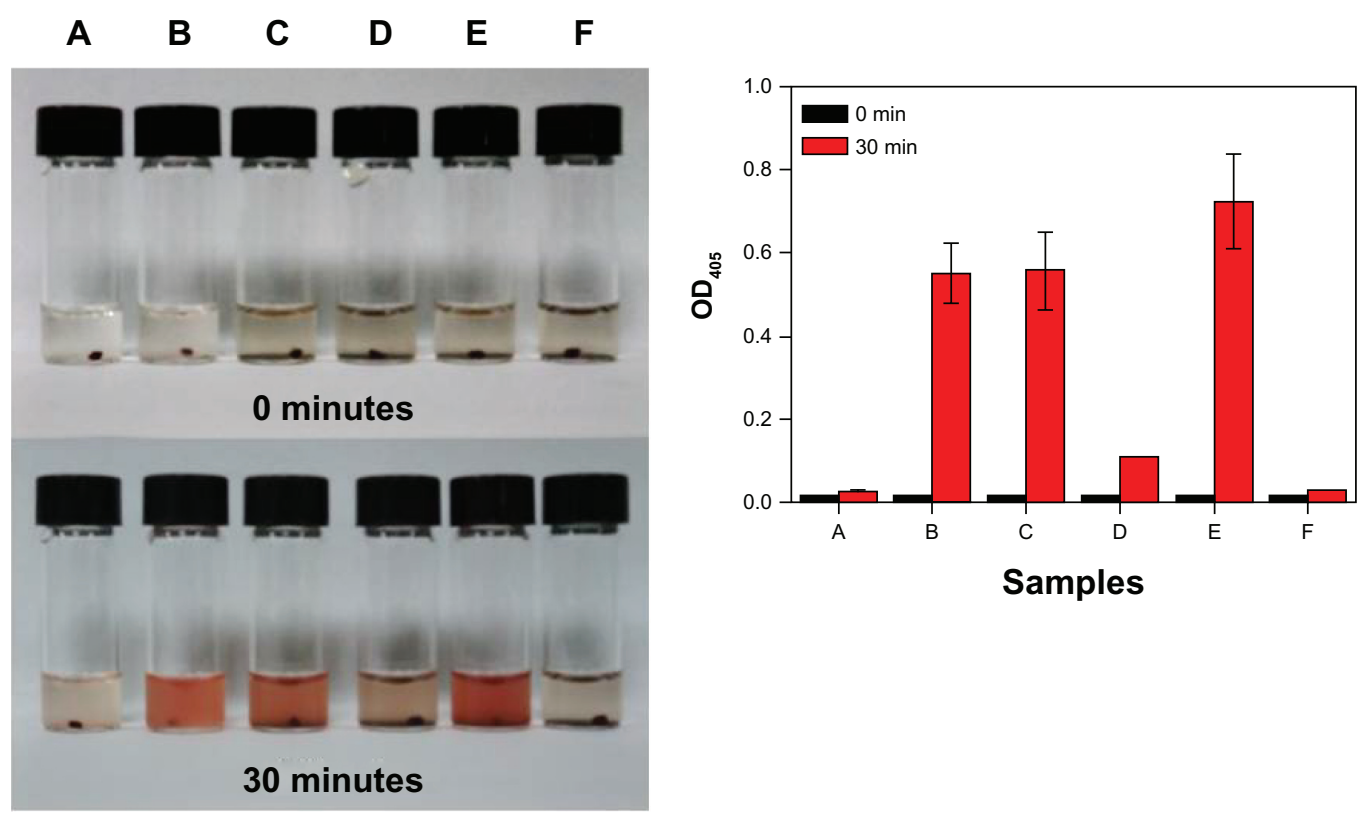

Figure 4 In vitro noncirculating thrombolysis induction. The in vitro noncirculating thrombolysis induced by (A) the control; (B) $62 \mu \mathrm{g}$ of free rtPA; (C) $62 \mu \mathrm{g}$ of effective rtPA in MNC-rtPA; (D) MNCs; (E) $62 \mu \mathrm{g}$ of effective rtPA in MNC-rtPA; and (F) MNCs with an applied magnetic field of 0.3-T (left); and their statistical illustration (right), Values are the means \pm SD $(n=3)$

Abbreviations: rtPA, recombinant tissue plasminogen activator; MNC, magnetic nanocarrier; $\mathrm{OD}_{405}$, optical density at $405 \mathrm{~nm}$; $\mathrm{SD}$, standard deviation.

observed shortly after tracer injection when compared with the other extremities (Figure 6A and C). The quantitative scintigraphic analysis revealed a maximum 4.97-fold increase in the relative counts in the leg compared with the arm at 650 seconds after injection (Figure 6B and D). The accumulation of ${ }^{99 \mathrm{~m}} \mathrm{Tc}-\mathrm{MNCs}$ in the soft tissue of the left hind limb decreased rapidly, but remained up to two-fold higher than that in the arm until the end of the study. In addition, the circulating ${ }^{99 \mathrm{~m}} \mathrm{Tc}-\mathrm{MNCs}$ distributed into the reticuloendothelial system, with the highest amounts found in the liver, spleen, and lung regions.

\section{In vivo thrombolysis}

Figure 7 illustrates the representative patterns of tissue flow responses to MNCs and MNC-rtPA following clot-induced ischemia. After the clot was introduced into the left iliac artery of the rat, the perfusion of the hind limb and the cremaster area was greatly reduced. Intra-arterial administration of the

\section{A 1 minute}
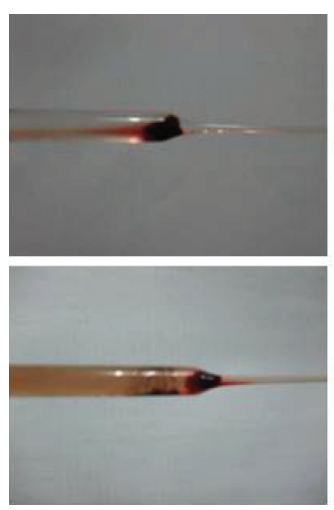

10 minutes

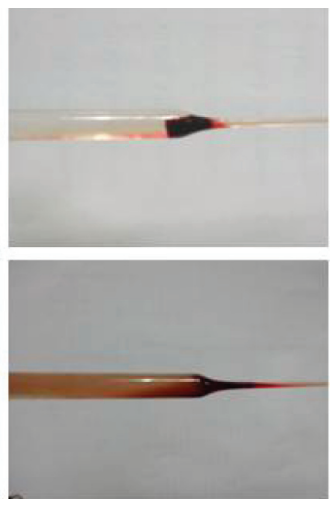

B

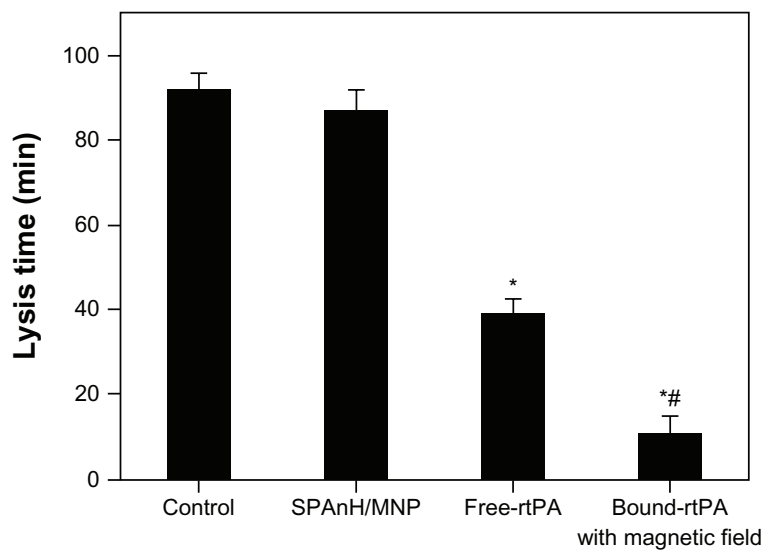

Figure 5 (A) The in vitro circulating thrombolysis induced by $250 \mu \mathrm{g}$ of free rtPA (top) or equivalent effective amount of rtPA in MNC-rtPA (bottom) with an applied magnetic field of 0.3-T. (B) The thrombolysis times of free rtPA and MNC-rtPA.

Notes: $* P<0.001$ compared with control; ${ }^{*} P<0.001$ compared with free rtPA. Values are the means $\pm S D(n=5)$.

Abbreviations: rtPA, recombinant tissue plasminogen activator; MNC, magnetic nanocarrier; T, Tesla; SPAnH, poly[aniline-co-N-(I-one-butyric acid) aniline]; SD, standard deviation. 


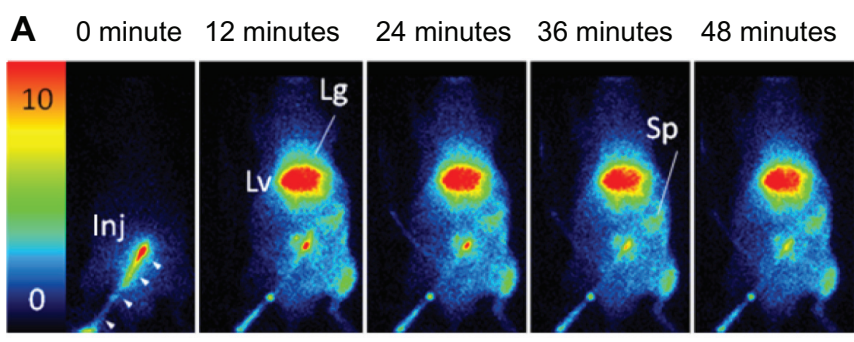

${ }^{99 m}$ TC-MNC biodistribution with magnetic guidance

C

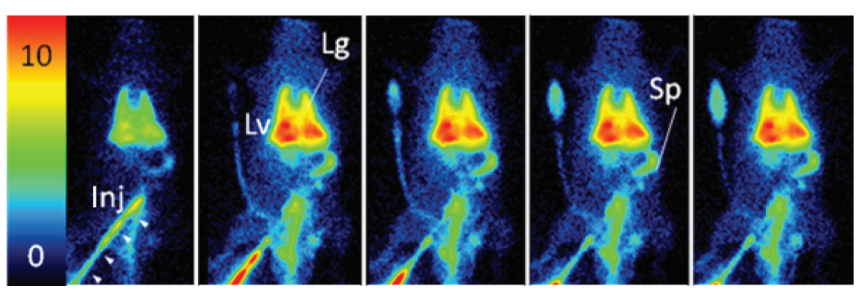

${ }^{99 m}$ TC-MNC biodistribution without magnetic guidance

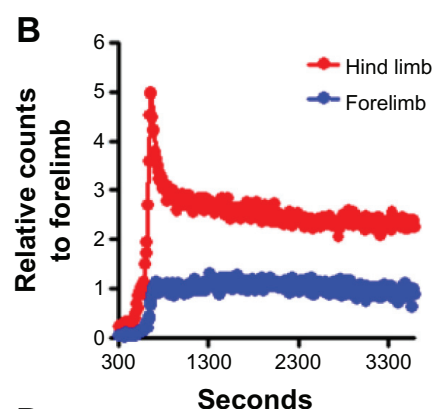

D

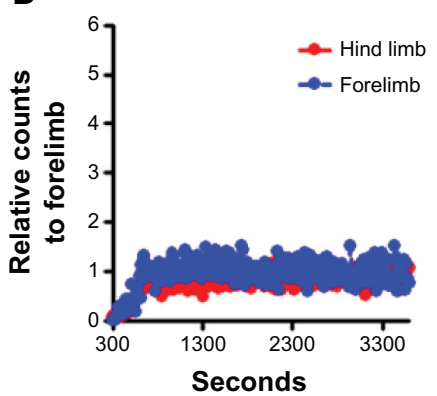

Figure 6 Dynamic scintigraphy of ${ }^{99 m} \mathrm{Tc}-\mathrm{MNC}$ biodistribution with $(\mathbf{A})$ and without $(\mathbf{C})$ magnetic guidance. The time versus relative radioactivity counts in the hind limb with respect to the forelimb were calculated for comparison (B and $\mathbf{D})$. Magnetic guidance was achieved by application of an NdFeB magnet (0.5-T) placed by the left iliac artery of the rat.

Note: The image intensity was normalized to the steady blood pool mean radioactivity counts in the forelimb region around 10 minutes post injection. Abbreviations: MNC, magnetic nanocarrier; Lg, lung; Lv, liver; Inj, injection site; Sp, spleen; arrow heads, catheter for tracer injection.

MNCs with magnetic guidance to achieve local retention did not improve the tissue perfusion throughout the 2-hour observation period (Figure 7A). In contrast, the intra-arterial administration of MNC-rtPA with an effective rtPA concentration of $0.2 \mathrm{mg} / \mathrm{kg}$ significantly restored the local tissue perfusion. MNC-rtPA restored the perfusion of the upper part of the hind limb and the cremaster muscle area within 30 minutes, followed by the lower part of the hind limb (Figure 7B); in some cases, the MNC-rtPA maximally restored the perfusion of the downstream tissue in 30 minutes (Figure 7C).

Laser Doppler signals in designated areas, as illustrated with squares in Figure 7A, were acquired for the quantitative
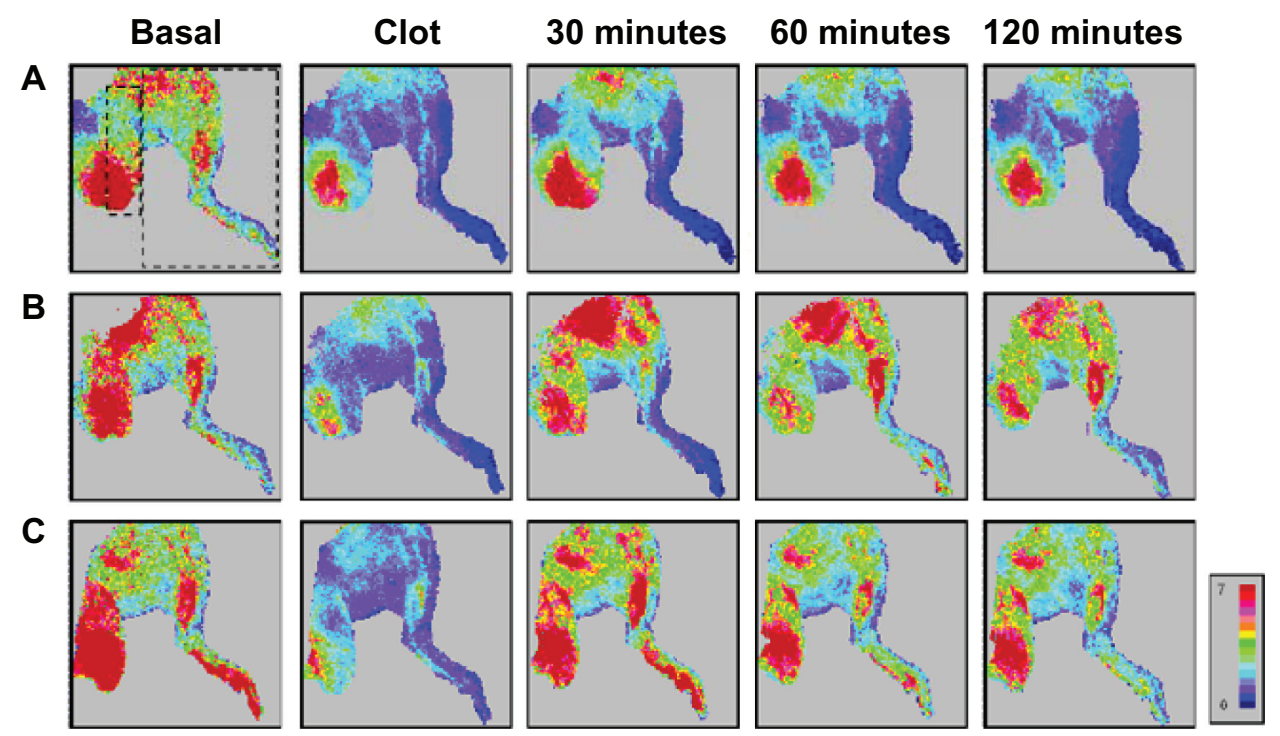

Figure 7 Representative results of the effects of MNC-rtPA on tissue perfusion in a rat embolism model. The tissue perfusion of the hind limb and cremaster area was measured with a laser Doppler perfusion imager. Five minutes after clot lodging, MNCs (I.I mg/kg) with (B and C) or without (A) MNC-rtPA (0.2 mg/kg) were administered from the right iliac artery under magnetic guidance. Laser Doppler signals in the designated areas, as illustrated with the squares in (A), were acquired for the quantitative analysis of hind limb versus cremaster perfusion.

Abbreviations: MNC, magnetic nanocarrier; rtPA, recombinant tissue plasminogen activator. 

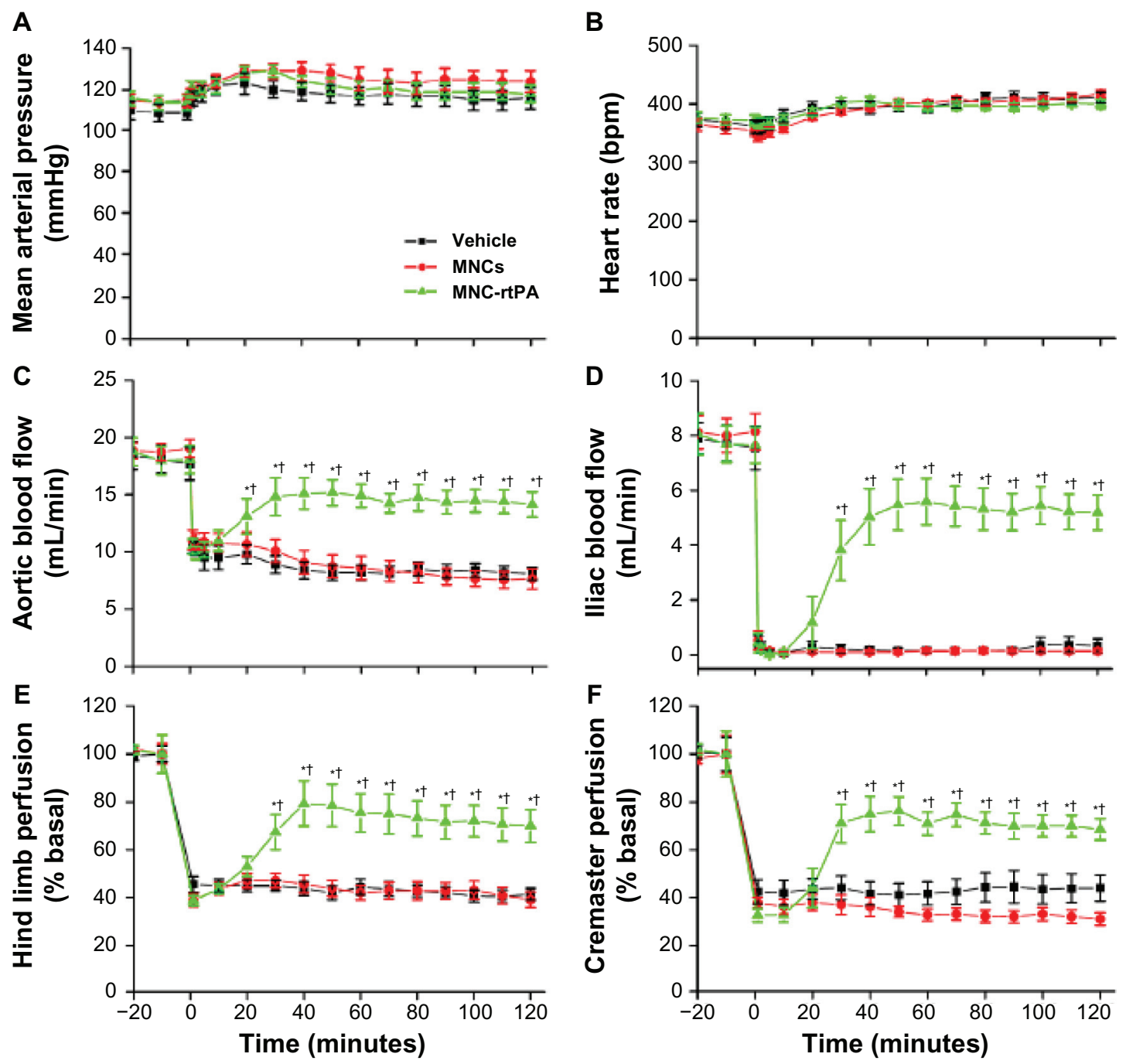

Figure 8 Thrombolytic effects of MNC-rtPA in a rat embolic model. The mean arterial pressure (A), heart rate (B), aortic blood flow (C), left iliac blood flow (D), left hind limb perfusion (E), and left cremaster perfusion (F) were measured before and after the introduction of a whole blood clot into the left iliac artery at time 0.

Notes: Vehicle $(n=8)$, MNCs $(I . I \mathrm{mg} / \mathrm{kg} ; \mathrm{n}=9)$, or MNC-rtPA $(0.2 \mathrm{mg} / \mathrm{kg}$ rtPA; $n=1 \mathrm{I})$ were administered from the right iliac artery 5 minutes after introducing the clot. Magnetic targeting was achieved by application of an external NdFeB magnet $(0.5-\mathrm{T})$ placed by the left iliac artery in all groups studied. Values are presented as the mean \pm SE. $* P<0.05$ compared with the corresponding MNC group. ${ }^{\dagger} P<0.05$ compared with the corresponding vehicle group.

Abbreviations: MNC, magnetic nanocarrier; rtPA, recombinant tissue plasminogen activator; T, Tesla.

analysis of the perfusion of the hind limb and the cremaster muscle (Figure 8), which are downstream vascular beds of the clot lodging. During the experiments, the mean arterial pressure and heart rate remained relatively stable, and no significant difference was observed among the groups (Figure 8A and B). After equilibration, the introduction of a whole blood clot reduced the abdominal aortic blood flow by $\sim 50 \%$ (Figure $8 \mathrm{C}$ ), which was associated with a near complete occlusion of the iliac artery (Figure 8D). Five minutes after the clot was lodged, MNCs $(1.1 \mathrm{mg} / \mathrm{kg})$ with and without immobilized $\mathrm{rtPA}(0.2 \mathrm{mg} / \mathrm{kg})$ were administered to the left iliac artery under magnetic guidance. MNC-rtPA significantly restored the aortic blood flow (Figure 8C), iliac blood flow (Figure 8D), hind limb perfusion (Figure 8E), and cremaster perfusion (Figure 8F) successively in 15 minutes to 25 minutes $(P<0.05)$; MNCs alone under magnetic guiding did not alter these parameters. Reperfusion time (50\%) of the iliac artery was $31 \pm 4$ minutes after administration of MNC-rtPA ( $\mathrm{n}=11$; Figure 8D). As early as 35 minutes after the administration of MNC-rtPA, the effects on the iliac blood flow reached a plateau and remained relatively stable until the end of the experiment.

In this study, no hemorrhage was observed in any of the rats studied. At the end of the experiments, no significant difference of quantity was observed in red blood cells, white blood cells, platelets, hemoglobin, or hematocrit among the groups of rats treated with vehicle, MNCs, or MNC-rtPA $(\mathrm{n}=6$; Table 1). 
Table I Hematological measurements in rats at the end of the experiments in Figure 8

\begin{tabular}{lllllll}
\hline Treatments & $\mathbf{n}$ & $\begin{array}{l}\text { RBC } \\
\left(10^{6} / \mathrm{mL}\right)\end{array}$ & $\begin{array}{l}\text { WBC } \\
\left(10^{3} / \mathrm{mL}\right)\end{array}$ & $\begin{array}{l}\text { Platelet } \\
\left(10^{3} / \mathrm{mL}\right)\end{array}$ & $\begin{array}{l}\text { HGB } \\
(\mathrm{g} / \mathrm{dL})\end{array}$ & $\begin{array}{l}\text { HCT } \\
(\%)\end{array}$ \\
\hline Vehicle & 6 & $7.4 \pm 0.3$ & $4.9 \pm 1.2$ & $602 \pm 55$ & $15 \pm 1$ & $49 \pm 2$ \\
MNCs & 6 & $8.1 \pm 0.2$ & $5.4 \pm 0.9$ & $565 \pm 57$ & $16 \pm 1$ & $53 \pm 1$ \\
MNC-rtPA & 6 & $8.0 \pm 0.1$ & $5.3 \pm 0.7$ & $619 \pm 25$ & $16 \pm 1$ & $52 \pm 1$ \\
\hline
\end{tabular}

Notes: Blood samples were collected from rats receiving vehicle, MNCs or MNCrtPA and analyzed. The concentrations of RBC, WBC, platelets, HGB, and HCT were determined.

Abbreviations: RBC, red blood cells; WBC, white blood cells; HGB, hemoglobin; HCT, hematocrit; MNCs, magnetic nanocarriers; rtPA, recombinant tissue plasminogen activator.

\section{Discussion}

In this study, we developed effective MNCs with a high loading capacity for rtPA and the ability to enhance the efficiency of a targeted therapy for thrombolysis in a rat embolism model. This advanced delivery system not only reduces the injection dose to prevent side effects, but it also increases the local concentration of rtPA at the clot site to accelerate the restoration of blood flow. The MNCs had a shell of water-soluble SPAnH polymer with polarons and bipolarons on the main chain arising from the protonation of the imine structure of SPAnNa by some of the carboxyl groups of the side chains and added $\mathrm{HCl}$. The resulting formation of many electron-hole pairs delocalized on the surface provided the MNCs with a high zeta potential $(40.6 \pm 0.7 \mathrm{mV})$, which was greater than the $30 \mathrm{mV}$ required to prevent aggregation and promote excellent stability in solution. ${ }^{36,37}$ These characteristics were confirmed by the electron spin resonance signal, which demonstrated a high concentration of polaron by the protonation on the main chain of SPAnH..$^{35}$ The resulting dispersion likely provided a large surface area, thereby increasing the opportunities for rtPA conjugation.

TEM was performed to evaluate the size and morphology of MNCs with core-shell structures, and electron diffraction analysis confirmed that the core of the MNCs was $\mathrm{Fe}_{3} \mathrm{O}_{4}$. The nanoscale size could provide a large surface area to increase the concentration of carboxyl groups, thereby resulting in greater rtPA conjugation. In addition, after coating, the SPAnH would not dissolve in aqueous solution, thus maintaining the quantity of carboxyl groups. The MNCs displayed superparamagnetic properties, which reflect their nanoscale size and single magnetic domain. ${ }^{38}$ The magnetization would be decreased after polymer coating and drug conjugation because of the proportional decrease in the amount of MNPs within one gram of MNCs and MNC-rtPA.

The binding capacity of rtPA per mg of MNCs increased with increasing concentrations of added rtPA, but saturation occurred because of the consumption of carboxyl functional groups on the surface of the MNCs. However, the specific activity decreased with increasing quantities of immobilized rtPA, which suggests that excessive rtPA binding to MNCs may result in higher steric hindrance. The high drug capacity of the drug-conjugated $(27.6 \mathrm{wt} \%)$ system was greater than that of the drug-encapsulated system by approximately two- to fourfold. ${ }^{10,39,40}$ In addition, the binding capacity was also much higher than that of a previous system in which PAA-MNPs were used as the nanocarrier for rtPA via covalent binding (276 $\mu \mathrm{g} \mathrm{rtPA} / \mathrm{mg}$ MNCs versus $67 \mu \mathrm{g} \mathrm{rtPA} / \mathrm{mg}$ PAA-MNPs), ${ }^{9}$ allowing for the reduction of MNCs required to deliver the same dosage of rtPA to achieve similar target thrombolysis. The polymer coating of the MNCs in the current study likely possessed a long side chain with four carbons that provided greater freedom of motion with less steric hindrance, whereas PAA chains tend to swell, extend, and dissolve in aqueous solution due to exhibition of $\mathrm{pH}$-dependent swelling behavior in the aqueous solution. ${ }^{41}$ Nevertheless, the enzyme activity associated with the PAA-coated carrier remained unchanged after 20 days in aqueous solution in storage, ${ }^{9}$ suggesting that the major advantages of the material in the current study may be due to their enhanced capacity for rtPA binding. The improved drug loading capacity may reduce $50 \%$ exposure of MNP in the body.

Although the limited freedom of the active sites reduced the original activity and binding affinity, it permitted excellent stability by restricting the conformation of the drug and preventing the distortion of the molecule. ${ }^{42}$ The increased thermal stability of MNC-rtPA could preserve its activity to enhance the drug preservation and extend the period available for MNC-rtPA to exert its therapeutic effects in vivo.

The kinetic parameters demonstrated a nucleophilic affinity between rtPA and the substrate; the affinity between rtPA and the substrate decreased as the $\mathrm{Km}$ value increased. These data indicate that the affinity of MNC-rtPA for the substrate decreased compared with the free rtPA. This difference may be related to the steric effects, structural changes, and limited freedom of the active site when rtPA was immobilized on the surface of the MNCs, thereby resulting in decreased accessibility of the substrate to the active sites of MNC-rtPA; ${ }^{13}$ however, the thermal stability of rtPA was increased. The overall efficacy of the thrombolysis catalyzed by MNC-rtPA should still be greater than that of free rtPA because MNCrtPA should be guided rapidly to the clot site to increase the local concentration of the rtPA.

During in vitro thrombolysis in the absence of circulation, the hemachrome measured for the clot lysed by MNC-rtPA 
was similar to that for the clot lysed by free rtPA, which indicates that the rtPA conjugated to the MNCs still maintained its thrombolytic function. However, the $\mathrm{OD}_{405}$ obviously increased when a magnetic field was applied under the vials during thrombolysis. The majority of the MNC-rtPA was likely influenced by the magnetic field and concentrated on the bottom of the vial, which resulted in a higher concentration of rtPA around the clots and more profound degradation. To simulate in vivo conditions, in vitro flow was added to the thrombolysis assay to test the efficiency of magnetic targeting and clot lysis. The clot lysis time for the MNC condition was similar to that of the control condition, which indicated that the MNCs did not necessarily exert any thrombolytic effect. However, the lysis time was decreased by $\sim 29$ minutes in the presence of MNC-rtPA with magnetic guidance compared with the free rtPA. This slower flow in the presence of free rtPA was induced by the blockade of the right channel with the clot, which caused the majority of the mobile solution (PPP) to flow out from the left channel, and the free rtPA at the injection site could not arrive efficiently and rapidly at the clot. However, the MNC-rtPA was guided efficiently from the injection site to the clot and concentrated around the clot to activate plasminogen to plasmin to dissolve the clot rapidly. These results indicate that the MNC-rtPA platform could enhance the drug delivery for thrombolysis and merits further in vivo study.

The biodistribution and magnetic guidance efficacy were evaluated by SPECT/CT. With magnetic guidance, the injected ${ }^{99 \mathrm{~m}} \mathrm{Tc}-\mathrm{MNCs}$ did not proceed to the liver and lung immediately; rather, they were concentrated at the injection site for up to 390 seconds. This effect differed from the high level of accumulation observed in the liver shortly after the administration of superparamagnetic iron oxide nanoparticles in humans. ${ }^{43}$ This guidance allowed for an increase of up to 4.97 -fold for ${ }^{99 \mathrm{~m}} \mathrm{Tc}-\mathrm{MNCs}$ in the hind limb compared with the forelimb at 650 seconds after injection. In animal studies, maximal targeting efficacy is critical; the targeting efficiency can be enhanced by increasing the strength of the magnetic field or the magnetization of the MNPs. However, a strong magnetic field of up to $14 \mathrm{~T}$ has been reported to affect the polymerization and degradation of fibrin. ${ }^{44}$ The static magnetic field $(0.5 \mathrm{~T})$ used during our thrombolytic treatment was low enough to prevent concern.

To our knowledge, the current rat embolic model was the first model illustrating hemodynamic changes before and after thrombolysis in different vascular beds downstream of the emboli (ie, hind limb and cremaster perfusion), and providing absolute blood flow changes in major arteries (ie, aorta and iliac artery). Observation of both vascular beds allowed for the evaluation of therapeutic efficacy of the targeting strategy, even when the magnetic guiding was conducted from the iliac to femoral artery, away from the pudic epigastric artery to the cremaster muscle. This is a critical demonstration of the effectiveness of the strategy that flow in the vascular bed downstream of the emboli, but away from the magnetic gradient, was also restored. Since the blood flow of the cremaster muscle was restored after the targeting therapeutics were administered, it is suggested that no clot piece in the pudic epigastric artery was left untreated after lodging of the emboli. It is likely that flow reduction in the cremaster bed was due to the emboli lodged in the iliac artery upstream of the pudic epigastric artery. Consistent with the previous studies, ${ }^{9,33}$ only $20 \%$ of the regular dose of rtPA was required with the targeting strategy in this model, which may greatly reduce the hemorrhagic side effects. In response to MNC-rtPA, the restoration of flow occurred almost simultaneously in hind limb and cremaster vascular beds (Figure 7C; Figure 8E versus F), suggesting the swiftness of the effect of MNC-rtPA. However, sequential restoration of hemodynamics along the hind limb perfusion may still occur in some cases (Figure 7B), suggesting that in response to MNC-rtPA, the emboli may further move downstream, and the area may experience increased perfusion with time. Nevertheless, MNCs did not exert a thrombolytic effect under a magnetic driving force per se (Figures 7A and 8), suggesting that the physical force generated by MNCs under magnetic guiding was not enough to cause an angioplasty-like effect. Differences in the kinetic profile of flow restoration induced by MNC-rtPA introduced variation in the quantitative results shown in Figure 8. Previous studies have demonstrated that free rtPA at $0.2 \mathrm{mg} / \mathrm{kg}$ did not restore hemodynamics after clot lodging, ${ }^{9}$ which further supports the idea that the magnetic carrier was effective in retaining rtPA at the target site under magnetic guiding. Further studies on parameters affecting the thrombolysis profiles, including speed of drug delivery and magnetic guiding strategy, may allow for optimization of both the platform and thus the outcome of the administered therapeutic medications.

In the previous study using PAA-MNP-rtPA under identical conditions, the time required for $50 \%$ restoration of the iliac flow averaged $42 \pm 7$ minutes $(n=7),{ }^{9}$ whereas in the current study, the $50 \%$ reperfusion time of the iliac artery was shortened by 11 minutes. The accelerated thrombolysis may be attributed to the significantly higher effective amount of rtPA per MNCs compared with other delivery systems..$^{7-9}$ In addition, the high rtPA capacity reduced the amount of 
MNCs required, and thus potentially reduced any possible toxic effects of MNCs. Our high-performing drug composite for thrombolysis treatment may benefit many patients who require conventional thrombolytic therapy.

\section{Conclusion}

In this study, rtPA was conjugated with MNCs to produce a targeting agent, which exerted a higher rtPA capacity and improved rtPA stability. MNC-rtPA with magnetic guidance successfully accelerated thrombolysis in clot-occluded tubes and in a rat embolic model with $20 \%$ of the regular dose of rtPA. Therefore, magnetically targeted thrombolysis may prevent hemorrhagic complications with great potential for the clinical treatment of thrombosis. Such drug-delivery systems may serve as a platform for the delivery of other plasminogen activators with lower substrate specificity at a lower cost and without any increase in the risk of hemorrhage.

\section{Acknowledgments and disclosure}

We thank the National Science Council of the Republic of China (NSC 99-2221-E-182-068, NSC 100-2120-M-182001, and NSC 94-2216-E-182-001), Chang Gung Memorial Hospital (CMRPD2A0041), Healthy Aging Research Program at Chang Gung University (EMRPD1A0841), and the Industrial Technology Research Institute (BF51RQ3100) for financial aid. The authors thank DrYing-Shiung Lee and Professor Yu-Sun Chang, who supported the nanomagnetic drug project at the Chang Gung Memorial Hospital and Chang Gung University, Chang Gung Molecular Medicine Research Center, 6 years ago, and the Chang Gung Memorial Hospital Microscopy Core Laboratory. The authors report no conflicts of interest in this work.

\section{References}

1. Harpel PC, Chang TS, Verderber E. Tissue plasminogen activator and urokinase mediate the binding of Glu-plasminogen to plasma fibrin I. Evidence for new binding sites in plasmin-degraded fibrin I. J Biol Chem. 1985;260(7):4432-4440.

2. Marder VJ. Thrombolytic therapy: 2001. Blood Rev. 2001;15(3): 143-157.

3. Andersen HR, Nielsen TT, Rasmussen K, et al; for DANAMI-2 Investigators. A comparison of coronary angioplasty with fibrinolytic therapy in acute myocardial infarction. $N$ Engl J Med. 2003;349(8): 733-742.

4. Madison EL, Coombs GS, Corey DR. Characterization of the fibrin independent specificity of t-PA for plasminogen. J Biol Chem. 1995; 270(13):7558-7562.

5. Hacke W, Kaste M, Fieschi C, et al. Randomized double-blind placebo-controlled trial of thrombolytic therapy with intravenous alteplase in acute ischaemic stroke (ECASS II). Second EuropeanAustralasian Acute Stroke Study Investigators. Lancet. 1998;352(9136): $1245-1251$.
6. Clark WM, Wissman S, Albers GW, Jhamandas JH, Madden KP, Hamilton S. Recombinant tissue-type plasminogen activator (Alteplase) for ischemic stroke 3 to 5 hours after symptom onset: The ATLANTIS Study: a randomized controlled trial. Alteplase Thrombolysis for Acute Noninterventional Therapy in Ischemic Stroke. JAMA. 1999;282(21): 2019-2026.

7. Leach JK, O'Rear EA, Patterson E, Miao Y, Johnson AE. Accelerated thrombolysis in a rabbit model of carotid artery thrombosis with liposome-encapsulated and microencapsulated streptokinase. Thromb Haemost. 2003;90(1):64-70.

8. Chung TW, Wang SS, Tsai WJ. Accelerating thrombolysis with chitosan-coated plasminogen activators encapsulated in poly-(lactideco-glycolide) (PLGA) nanoparticles. Biomaterials. 2008;29(2): 228-237.

9. Ma YH, Wu SY, Wu T, Chang YJ, Hua MY, Chen JP. Magnetically targeted thrombolysis with recombinant tissue plasminogen activator bound to polyacrylic acid-coated nanoparticles. Biomaterials. 2009; 30(19):3343-3351.

10. Xie Y, Kaminski MD, Torno MD, Finck MR, Liu X, Rosengart AJ. Physicochemical characteristics of magnetic microspheres containing tissue plasminogen activator. J Magn Magn Mater. 2007;311(1): 376-378.

11. Bi F, Zhang J, Su Y, Tang YC, Liu JN. Chemical conjugation of urokinase to magnetic nanoparticles for targeted thrombolysis. Biomaterials. 2009;30(28):5125-5130.

12. Torno MD, Kaminski MD, Xie Y, et al. Improvement of in vitro thrombolysis employing magnetically-guided microspheres. Thromb Res. 2008;121(6):799-811.

13. Hong J, Xu D, Gong P, Yu J, Ma H, Yao S. Covalent-bonded immobilization of enzyme on hydrophilic polymer covering magnetic nanogels. Microporous Mesoporous Mater. 2008;109:470-477.

14. Dobson J. Magnetic nanoparticles for drug delivery. Drug Dev Res. 2006;67(1):55-60.

15. Horák D, Babic M, Macková H, Benes MJ. Preparation and properties of magnetic nano- and microsized particles for biological and environmental separations. J Sep Sci. 2007;30(11):1751-1772.

16. Gamarra LF, Brito GES, Pontuschka WM, Amaro E, Parma AHC, Goya GF. Biocompatible superparamagnetic iron oxide nanoparticles used for contrast agents: a structural and magnetic study. J Magn Magn Mater. 2005;289:439-441.

17. Cheng FY, Su CH, Yang YS, et al. Characterization of aqueous dispersions of $\mathrm{Fe}(3) \mathrm{O}(4)$ nanoparticles and their biomedical applications. Biomaterials. 2005;26(7):729-738

18. Hua MY, Yang HW, Liu HL, et al. Superhigh-magnetization nanocarrier as a doxorubicin delivery platform for magnetic targeting therapy. Biomaterials. 2011;32(34):8999-9010.

19. Lee G, Kim J, Lee J-H. Development of magnetically separable polyaniline nanofibers for enzyme immobilization and recovery. Enzyme Microb Technol. 2008;42(6):466-472.

20. Lee D-G, Ponvel KM, Kim M, Hwang S, Ahn IS, Lee CH. Immobilization of lipase on hydrophobic nano-sized magnetite particles. J Mol Catal B Enzym. 2009;57(1-4):62-66.

21. Liberti PA, Rao CG, Terstappen LWMM. Optimization of ferrofluids and protocols for the enrichment of breast tumor cells in blood. J Magn Magn Mater. 2001;225(1-2):301-307.

22. Sonvico F, Mornet S, Vasseur S, et al. Folate-conjugated iron oxide nanoparticles for solid tumor targeting as potential specific magnetic hyperthermia mediators: synthesis, physicochemical characterization, and in vitro experiments. Bioconjug Chem. 2005; 16(5):1181-1188.

23. Kohler N, Sun C, Wang J, Zhang M. Methotrexate-modified superparamagnetic nanoparticles and their intracellular uptake into human cancer cells. Langmuir. 2005;21(19):8858-8864.

24. Zhang JL, Srivastava RS, Misra RD. Core-shell magnetite nanoparticles surface encapsulated with smart stimuli-responsive polymer: synthesis, characterization, and LCST of viable drug-targeting delivery system. Langmuir. 2007;23(11):6342-6351. 
25. Zhang Y, Zhang J. Surface modification of monodisperse magnetite nanoparticles for improved intracellular uptake to breast cancer cells. J Colloid Interface Sci. 2005;283(2):352-357.

26. Hu F, Li Z, Tu C, Gao M. Preparation of magnetite nanocrystals with surface reactive moieties by one-pot reaction. J Colloid Interface Sci. 2007;311(2):469-474.

27. Hua MY, Yang HW, Chuang CK, et al. Magnetic-nanoparticle-modified paclitaxel for targeted therapy for prostate cancer. Biomaterials. 2010;31(28):7735-7763.

28. Hua MY, Liu HL, Yang HW, et al. The effectiveness of a magneticnanoparticle-based delivery system for BCNU in the treatment of gliomas. Biomaterials. 2011;32(2):516-527.

29. Yang HW, Hua MY, Liu HL, et al. Self-protecting core-shell magnetic nanoparticles for targeted, traceable, long half-life delivery of BCNU to gliomas. Biomaterials. 2011;32(27):6523-6532.

30. Fang N, Tan WJ, Leong KW, Mao HQ, Chan V. pH responsive adhesion of phospholipid vesicle on poly(acrylic acid) cushion grafted to poly(ethylene terephthalate) surface. Colloids Surf B Biointerfaces. 2005;42(3-4):245-252.

31. Kouassi GK, Irudayaraj J, McCarty G. Examination of cholesterol oxidase attachment to magnetic nanoparticles. J Nanobiotechnology. 2005;3(1):1.

32. Ye P, Xu ZK, Che AF, Wu J, Seta P. Chitosan-tethered poly(acrylonitrileco-maleic acid) hollow fiber membrane for lipase immobilization. Biomaterials. 2005;26(32):6394-6403.

33. Ma YH, Hsu YW, Chang YJ, Hua MY, Chen JP, Wu T. Intra-arterial application of magnetic nanoparticles for targeted thrombolytic therapy: a rat embolic model. J Magn Magn Mater. 2007;311(1):342-346.

34. Ma HL, Qi XR, Maitani Y, Nagai T. Preparation and characterization of superparamagnetic iron oxide nanoparticles stabilized by alginate. Int J Pharm. 2007;333(1-2):177-186.
35. Chen SA, Hwang GW. Water-soluble self-acid-doped conducting polyaniline: structure and properties. J Am Chem Soc. 1995;117(40): 10055-10062.

36. Luthra V, Singh R, Gupta SK, Mansingh A. Mechanism of dc conduction in polyaniline doped with sulfuric acid. Current Applied Physics. 2003;3(2-3):219-222.

37. Liao DL, Wu GS, Liao BQ. Zeta potential of shape-controlled TiO2 nanoparticles with surfactants. Colloids Surf A Physicochem Eng Asp. 2009;348(1-3):270-275.

38. Mandzy N, Grulke E, Druffel T. Breakage of TiO2 agglomerates in electrostatically stabilized aqueous dispersions. Powder Technol. 2005;160(2):121-126.

39. Zhang HZ, Gao FP, Liu LR, et al. Pullulan acetate nanoparticles prepared by solvent diffusion method for epirubicin chemotherapy. Colloid Surf B Biointerfaces. 2009;71(1):19-26.

40. Wang YS, Liu LR, Jiang Q, Zhang QQ. Self-aggregated nanoparticles of cholesterol-modified chitosan conjugate as a novel carrier of epirubicin. Eur Polym J. 2007;43(1):43-51.

41. Li Y, Zhang Y, Yang D, et al. PAA-g-PPO amphiphilic graft copolymer: synthesis and diverse micellar morphologies. Macromolecules. 2010; 43(1):262-270.

42. Dessouki AM, Atia KS. Immobilization of adenosine deaminase onto agarose and casein. Biomacromolecules. 2002;3(3):432-437.

43. Hamm B, Staks T, Taupitz M, et al. Contrast-enhanced MR imaging of liver and spleen: first experience in humans with a new superparamagnetic iron oxide. J Magn Reson Imaging. 1994;4(5):659-668.

44. Iwasaka M, Takeuchi M, Ueno S, Tsuda H. Polymerization and dissolution of fibrin under homogeneous magnetic fields. J Appl Phys. 1998;83(11):6453-6455. 


\section{Supplementary materials Experimental details}

Materials

Succinic anhydride was purchased from MP Biomedicals (MP Biomedicals LLC, Singapore). Aluminum chloride and 1-methyl-2-pyrrolidone (NMP) were purchased from ACROS (Thermo Fisher Scientific, Geel, Belgium). Aniline monomer, ammonium peroxydisulfate (98\%), hydrochloric acid (37\%), sodium hydroxide, iron (2) chloride, and iron (3) chloride were purchased from Merck (Merck and Co, Inc, Whitehouse Station, NJ). NMP and the aniline monomer were distilled under reduced pressure before use. 1-Ethyl-3-(3-dimethylaminopropyl)carbodiimide hydrochloride, 2-( $N$-morpholino) ethanesulfonic acid hydrate, sodium bicarbonate, XTT sodium salt, phosphate-buffered saline, trypsin, Inactin ${ }^{\circledR}$, heparin, $\mathrm{N}$-hydroxysulfosuccinimide sodium salt, and fetal bovine serum were purchased from Sigma (Sigma-Aldrich Co).

Human umbilical vein endothelial cells were purchased from the Bioresource Collection and Research Center (Taiwan, Republic of China). Gentamycin, penicillin, and streptomycin were purchased from MdBio (Piscataway, NJ). Endothelial cell growth supplement (ECGS) was purchased from Millipore (Millipore Corporation, Billerica, MA). The protein assay dye reagent was purchased from Bio-Rad (Hercules, CA). rtPA was obtained from Boehringer Ingelheim (Mannheim, Germany). The substrate for the rtPA activity measurements (S-2288 $\left.{ }^{\mathrm{TM}}\right)$ was purchased from Chromogenix (Milano, Italy). The Live/Dead Viability/ Cytotoxicity Kit, Medium 199 (M199) and Hank's balanced salt solution (HBSS) were purchased from Invitrogen (Life Technologies Corporation, Carlsbad, CA). DI water was used in all experiments.

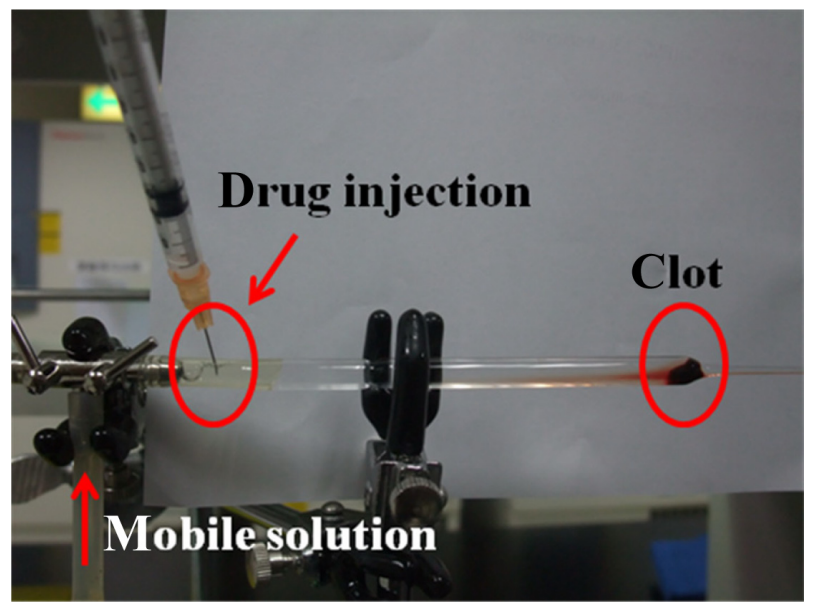

Figure SI The laboratory set-up for determining the efficacy of targeted thrombolysis in vitro.

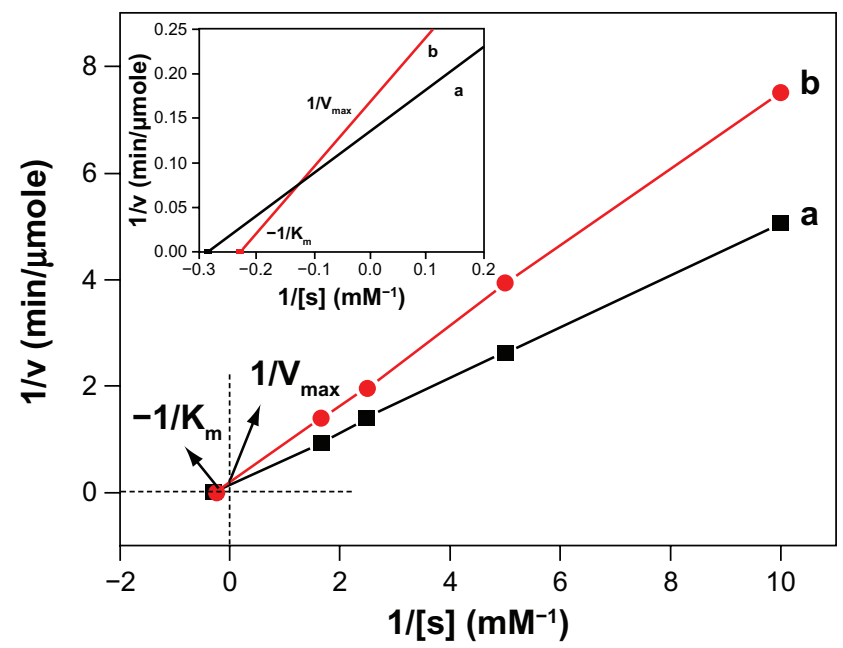

Figure S2 Lineweaver-Burk plots of (a) free rtPA and (b) MNC-rtPA.

Abbreviations: rtPA, recombinant tissue plasminogen activator; MNC, magnetic nanocarrier.

\section{Activity and stability assays for MNC-rtPA}

The activity of rtPA was measured spectrophotometrically using the specific chromogenic substrate (S-2288 ${ }^{\mathrm{TM}}$ ) for rtPA. A $50-\mu \mathrm{L}$ aliquot of MNC-rtPA solution was reacted with $350 \mu \mathrm{L}$ of Tris-buffer ( $\mathrm{pH} \mathrm{8.4)} \mathrm{and} 200 \mu \mathrm{L}$ of S-2288TM at $25^{\circ} \mathrm{C}$ for 30 seconds; the reaction was then stopped by adding $100 \mu \mathrm{L}$ of acetic acid (20 wt $\%$ ). The absorbance of $\rho$-nitroaniline was measured at $405 \mathrm{~nm}$ $\left(\mathrm{OD}_{405}\right)$ in a spectrophotometer. The activity (U) of each sample was calculated as follows: $\mathrm{OD}_{405} \times 0.104 \times$ total volume $(\mathrm{mL}) /$ reaction time (minutes). The relative activity after bioconjugation was defined as the specific activity $\left(\mathrm{U} / \mathrm{mg}\right.$ ) of MNC-rtPA compared to that of free $\mathrm{rtPA}$ at $25^{\circ} \mathrm{C}$

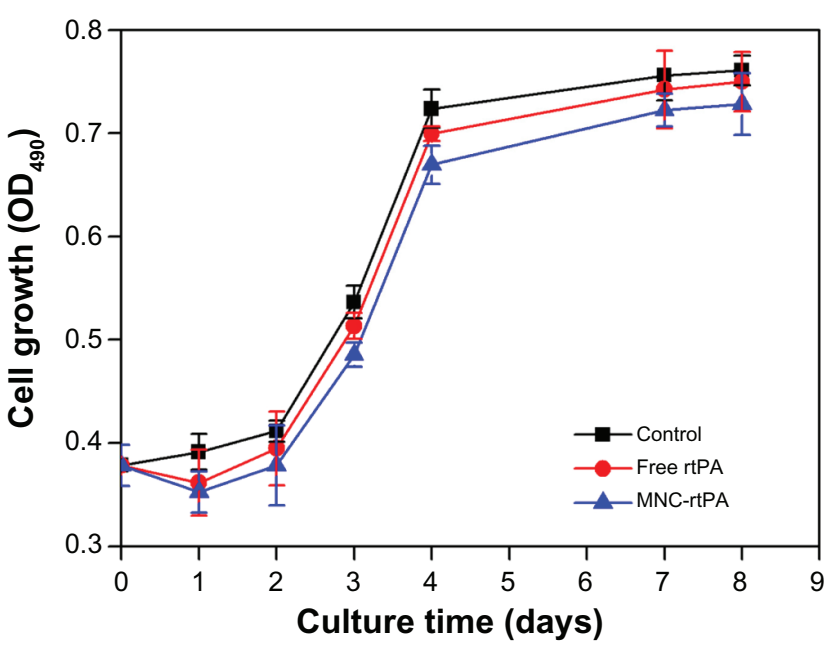

Figure S3 Cytotoxicity of free rtPA and MNC-rtPA in HUVECs. Note: Values are the means \pm SD $(n=8)$.

Abbreviations: rtPA, recombinant tissue plasminogen activator; MNC, magnetic nanocarrier; HUVECs, human umbilical vein endothelial cells. 
and expressed as a percentage. The effective rtPA of MNCrtPA was defined by the result of immobile rate multiplied by relative activity. Additionally, the stability of free rtPA and $\mathrm{MNC}$-rtPA stored at $4{ }^{\circ} \mathrm{C}, 25^{\circ} \mathrm{C}$ and $37^{\circ} \mathrm{C}$ for $1-35$ days was analyzed with the above activity assay method. The reaction mechanism between $\mathrm{rtPA}$ and $\mathrm{S}-2288^{\mathrm{TM}}$ was the following:

$$
\begin{aligned}
& \text { H-D-lle-Pro-Arg- } \rho \mathrm{NA}+\mathrm{H}_{2} \mathrm{O} \\
& \stackrel{r t P A}{\longrightarrow} \mathrm{H}-\mathrm{D}-1 \text { lle-Pro-Arg-OH }+\rho \mathrm{NA}
\end{aligned}
$$

\section{In vitro cytotoxicity study}

HUVECs were cultured in M199 supplemented with $2.2 \mathrm{mg} / \mathrm{mL}$ sodium bicarbonate, $10 \%$ fetal bovine serum, $50 \mu \mathrm{g} / \mathrm{mL}$ gentamycin, $50 \mu \mathrm{g} / \mathrm{mL}$ penicillin, $50 \mu \mathrm{g} / \mathrm{mL}$ streptomycin, $25 \mathrm{U} / \mathrm{mL}$ heparin, and $30 \mu \mathrm{g} / \mathrm{mL}$ ECGS at $37^{\circ} \mathrm{C}$ and $5 \% \mathrm{CO}_{2}$ for 48 hours. Approximately 10,000 cells (ie, $150 \mu \mathrm{L}$ of a suspension of $6.67 \times 10^{4}$ cells $/ \mathrm{mL}$ ) were placed in each well of a $1 \%$ gelatin-coated 96 -well culture plate, which was incubated in a humidified chamber at $37^{\circ} \mathrm{C}$ under $5 \% \mathrm{CO}_{2}$ for 48 hours. Then, $50 \mu \mathrm{L}$ of different concentrations of MNCs in M199 were added, and the culture was continued. Cells were also cultured in the presence of an 0.08-T magnetic field applied beneath the culture plate. The cell proliferation was determined by counting after 48 hours. Before counting, the culture medium was removed, and the cells were incubated in $120 \mu \mathrm{L}$ XTT for 3 hours. After the reaction, $100 \mu \mathrm{L}$ of the XTT solution was sampled from each well and transferred to a 96-well counting dish. The cytotoxicity of MNCs in HUVECs in vitro was evaluated by measuring the OD at $490 \mathrm{~nm}$ using an ELISA reader.

In a separate series of experiments, $2 \mathrm{~mL}$ of HUVECs $(10,000$ cells $/ \mathrm{mL})$ was plated in $35-\mathrm{mm}$-diameter dishes that were coated with $1 \%$ gelatin, and the cells were cultured in a humidified chamber at $37^{\circ} \mathrm{C}$ under $5 \% \mathrm{CO}_{2}$ for 48 hours. Then, $100 \mu \mathrm{L}$ of MNCs ( $4 \mathrm{mg} / \mathrm{mL}$ ) in M199 was added, and the incubation was continued for 1-7 days. The medium was removed, the cells were washed with $1 \mathrm{~mL}$ of HBSS, and $1 \mathrm{~mL}$ of LIVE/DEAD reagent was added. After 30 minutes, the reagent was removed, and the cells were washed again with HBSS. The cytotoxicity was monitored with a TCS SP2 confocal spectral microscope (Leica Microsystems $\mathrm{GmbH}$, Wetzlar, Germany).
International Journal of Nanomedicine

\section{Publish your work in this journal}

The International Journal of Nanomedicine is an international, peerreviewed journal focusing on the application of nanotechnology in diagnostics, therapeutics, and drug delivery systems throughout the biomedical field. This journal is indexed on PubMed Central,

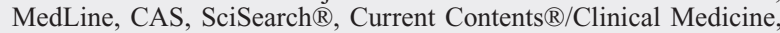

\section{Dovepress}

Journal Citation Reports/Science Edition, EMBase, Scopus and the Elsevier Bibliographic databases. The manuscript management system is completely online and includes a very quick and fair peer-review system, which is all easy to use. Visit http://www.dovepress.com/ testimonials.php to read real quotes from published authors. 